\title{
26461 - INDEPENDENT PREDICTORS OF POSTOPERATIVE DELIRIUM AFTER CARDIAC SURGERY
}

\author{
Rita Katznelson MD, Scott Beattie, MD PhD; Leonid Minkovich, MD PhD; Zeev \\ Freidman, George Djaini, MD \\ Toronto General Hospital, UHN, Toronto, ONTARIO, Canada
}

INTRODUCTION: Delirium is an acute deterioration of brain function characterized by fluctuating consciousness and an inability to maintain attention. It is serious complication after cardiac surgery that occurs in up to $47 \%$ of patients and results in prolonged length of stay (LOS) and health care costs.(1-3) The objective of this study was to identify the independent perioperative predictors of delirium in a cohort of cardiac surgical patients. METHODS: After REB approval, data were prospectively collected on consecutive patients undergoing cardiac surgery with cardiopulmonary bypass (CPB) from April to September 2005 in an academic hospital. All patients were screened for delirium during their hospitalization in the cardiovascular intensive care unit every 12 hours postoperatively using the Confusion Assessment Method in Intensive Care Unit (CAMICU). The CAM-ICU monitors for delirium in both ventilated and extubated patients. It based on the Diagnostic and Statistical Manual of Mental Disorders criteria and includes four-step algorithm assessing 1) an acute onset of changes or fluctuations in the course of mental status, 2) inattention, 3) disorganized thinking and 4) an altered level of consciousness. The patient is determined to be delirious (CAM positive) if he/she manifests both features 1 and 2, plus either feature 3 or 4 .

Multivariable logistic regression analysis was used to identify the independent perioperative predictors of delirium after cardiac surgery.

RESULTS: Of the 479 patients analyzed, 63 (13\%) patients were diagnosed with postoperative delirium. Delirium patients had markedly $(\mathrm{P}<0.001)$ longer hospital LOS (10, 7-18 days versus 6, 5-8 days) (median; interquartile range) and ICU LOS (4, 2-6 days versus 1, 1-3 days). Independent predictors of delirium identified by multivariable logistic regression are demonstrated in the Table. The model was reliable (HosmerLemeshow test $\mathrm{P}=0.3$ ) and discriminative (area under ROC curve $=0.80$ ). Of note, the following variables did not remain in the model: type and urgency of procedure; history of hypertension, diabetes, congestive heart failure, and left ventricular dysfunction; infection, re-exploration, and low output syndrome.

CONCLUSIONS: Delirium after cardiac surgery with CPB was a common and serious complication. Treatment of modifiable risk factors as massive blood transfusion and postoperative atrial fibrillation may decrease the risk of delirium and improve outcome. REFERENCE: 1. J Psychosom Res 1996; 41(1):13-30, 2.Crit Care 2005; 9(4):R375R381. 3.Crit Care Med 2004; 32(4):955-962. 
Table Independent predictors of postoperative delinum

\begin{tabular}{|l|c|c|c|c|}
\hline \multicolumn{1}{|c|}{ Variable } & $\begin{array}{c}\text { Wald } \\
\text { Chi-Square }\end{array}$ & $\begin{array}{c}\text { Odds } \\
\text { Ratio }\end{array}$ & $\begin{array}{c}95 \% \text { Confidence } \\
\text { Interval }\end{array}$ & P value \\
\hline $\begin{array}{l}\text { Preop renal dysfimction } \\
\text { (creatinine }>110 \text { mmolL) }\end{array}$ & 12.05 & 2.8 & $1.43-13.5$ & 0.0005 \\
\hline RBC transfision > 4 units & 7.02 & 1.8 & $0.76-4.4$ & 0.03 \\
\hline Periogerative IABP & 6.66 & 4.4 & $1.42-13.51$ & 0.009 \\
\hline Postoperative renal failure & 5.54 & 8.6 & $1.4-51.6$ & 0.02 \\
\hline Prolonged CPB time (min) & 4.85 & 1.01 & $1.001-1.015$ & 0.03 \\
\hline Older age (years) & 4.77 & 1.03 & $1.003-1.06$ & 0.03 \\
\hline Postop atrial fibrillation & 4.00 & 1.91 & $1.01-3.6$ & 0.04 \\
\hline
\end{tabular}

